\title{
Transapical valve-in-valve implantation to treat a regurgitant mitral bioprothesis in a child with failing Fontan circulation
}

\author{
Axel Moysich, MD, Gunter Kerst, MD, Hakan Akintürk, MD, and Dietmar Schranz, MD, Giessen, \\ Germany
}

See related commentary on pages e25-6.

Video clip is available online.

This report describes the first-in-human successful transapical transcatheter mitral valve replacement in a child with complex heart disease and a Fontan circulation. Transapical transcatheter implantation of a Melody valve (Medtronic plc, Minneapolis, Minn) in a mitral bioprosthesis is feasible even in a young child.

\section{CLINICAL SUMMARY}

A 3.5-year-old girl (body weight of $15 \mathrm{~kg}$ ) with plastic bronchitis and progressive Fontan circulation failure was referred for a heart transplant. She had a diagnosis of situs inversus and dextrocardia, asplenia, unbalanced complete atrioventricular septal defect with a dominant left ventricle, and transposition of the great arteries. A bidirectional Glenn anastomosis, followed by a fenestrated Fontan procedure with an extra-cardiac 16-mm conduit, had been performed (Figure 1). Because of severe atrioventricular valve (AVV) regurgitation, the right ventricular AVV had been surgically closed and a 27-mm mitral valve bioprosthesis (Mosaic Tissue Valve; Medtronic) had been implanted into the left ventricular AVV. Six months later, a severely regurgitant and mildly stenotic bioprosthesis led to severe heart failure (Ross heart failure class IV) and to referral to our center (Video 1). Because of a severely degenerated mitral bioprosthesis and the patient's poor clinical functional status, transapical valve-in-valve implantation of a customized Melody valve was considered and discussed in detail with the parents as an alternative therapeutic option to surgical valve re-replacement or heart transplant listing. After informed,

\footnotetext{
From the Pediatric Heart Center, Justus-Liebig-University Giessen, Giessen, Germany.

Disclosures: Authors have nothing to disclose with regard to commercial support.

Received for publication Jan 29, 2015; revisions received April 13, 2015; accepted for publication May 3, 2015; available ahead of print June 3, 2015.

Address for reprints: Dietmar Schranz, MD, Pediatric Heart Center, Justus Liebig-

University Giessen, Feulgenstrasse 12, 35385 Giessen, Germany (E-mail: Dietmar. Schranz@paediat.med.uni-giessen.de).

J Thorac Cardiovasc Surg 2015;150:e23-5 $0022-5223 / \$ 36.00$

Copyright (c) 2015 Published by Elsevier Inc. on behalf of The American Association for Thoracic Surgery

http://dx.doi.org/10.1016/j.jtcvs.2015.05.008
}

written consent was obtained in agreement with guidelines of our hospital ethics committee, cardiac catheterization was performed with the patient under general endotracheal anesthesia. Systemic venous and corresponding mean pulmonary arterial pressures were increased to $23 \mathrm{~mm} \mathrm{Hg}$, associated with pulmonary capillary wedge pressures of $14 \mathrm{~mm}$ $\mathrm{Hg}$ at a systemic end-diastolic ventricular pressure of 9 $\mathrm{mm} \mathrm{Hg}$, which indicated precapillary and postcapillary components of elevated mean pulmonary arterial pressure. Under transesophageal echocardiographic and fluorescence guidance, minimally invasive right thoracotomy in the fifth intercostal space in the lateral axillary line was performed. The pericardium was opened, and a muscular area was identified for transapical access. After establishment of a perpendicular mattress of 3.0 polypropylene purse-string sutures for bleeding control and subsequent sealing, temporary pacing wires were placed to the epicardial surface and heparin was administered intravenously. With a modified Seldinger technique, transapical access was gained by puncture of the left ventricular apex and advancement of a hydrophilic wire of an $11 \mathrm{~F}$ sheath (Terumo Medical Corporation, Somerset, NJ) from the ventricular apex through the mitral bioprosthesis into the left atrium. After a $10 \mathrm{~F}$ sheath was advanced over the wire into the left atrium, an Amplatz Super Stiff 0.035-inch guidewire (Boston Scientific Corporation, Marlborough, Mass) was positioned in the left upper pulmonary vein. The orifice diameters of the mitral bioprosthesis were $13 \times 16 \mathrm{~mm}$ by transesophageal echocardiography and $17.2 \mathrm{~mm}$ by balloon sizing. with a $25-\mathrm{mm}$ PTS sizing balloon catheter (pfm medical ag, Cologne, Germany; Figure 2, A). After replacement of the $10 \mathrm{~F}$ sheath with a $21 \mathrm{~F}$ Edwards introducer set (Edwards Lifesciences Corporation, Irvine, Calif; Figure 2, B), a Melody valve was hand crimped on a $22 \times 40$-mm balloon-in-balloon catheter (pfm medical), with the inflow portion directed to the balloon tip and advanced through the $21 \mathrm{~F}$ sheath. To avoid left ventricular outflow tract obstruction, the proximal end of the valved stent was positioned exactly at the ventricular end of the frame of the bioprosthesis (Figure 2,C). The small intracardiac dimensions left little space for positioning the $21 \mathrm{~F}$ sheath within the left ventricular cavity with the distal portion of the valved stent sufficiently distant from the posterior "left" atrial wall (Figure 2, $C$, and Video 3). After valve-in-valve implantation (Video 2), regurgitation was reduced to mild (Figure 2, D, and Video 3), leading to a decrease in mean pulmonary arterial pressure of $15 \mathrm{~mm}$ Hg. The intervention was terminated uneventfully by removing the stiff guidewire and the $21 \mathrm{~F}$ sheath, sealing 


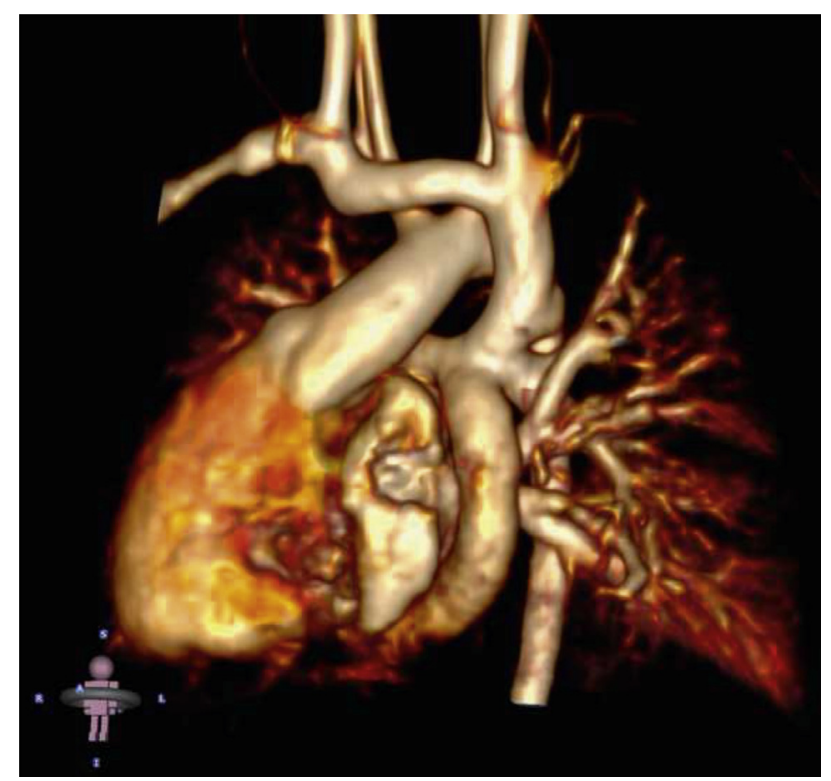

FIGURE 1. Three-dimensional reconstructed magnetic resonance image showing dextrocardia of the univentricular heart with left-sided total cavopulmonary connection.

the transapical access by the purse-string sutures and closing the chest. Despite plastic bronchitis, the toddler could be weaned from the ventilator without difficulties.
Heart failure symptoms rapidly improved to Ross heart failure class II.

\section{DISCUSSION}

AVV regurgitation may lead to a failing Fontan circulation with development of plastic bronchitis through an increase of "left" atrial and consecutively increased pulmonary arterial pressures as well as by a low cardiac output, resulting in alteration of bronchial mucosal integrity. ${ }^{1}$ Valve replacement by a bioprosthesis remains a short-term or midterm palliation ${ }^{2}$ that is associated with a high procedural risk when re-replacement becomes necessary. Addressing the special needs of children for a valve that can be accommodated to somatic growth, off-label use of a balloondilatable Melody valve for mitral valve replacement by heart surgery has recently been reported. ${ }^{3}$ Transvenous antegrade Melody valve-in-valve implantation in mitral position by means of a completely percutaneous, transseptal-transapical arteriovenous rail has been described in a limited number of adult patients. ${ }^{4,5}$ Here we show that transapical implantation of a customized Melody valve in a mitral bioprosthesis significantly reduced regurgitation. Improved AVV function resulted in a superior Fontan circulation and alleviated heart failure symptoms. Because of the shortterm follow-up, however, we cannot yet report on the further
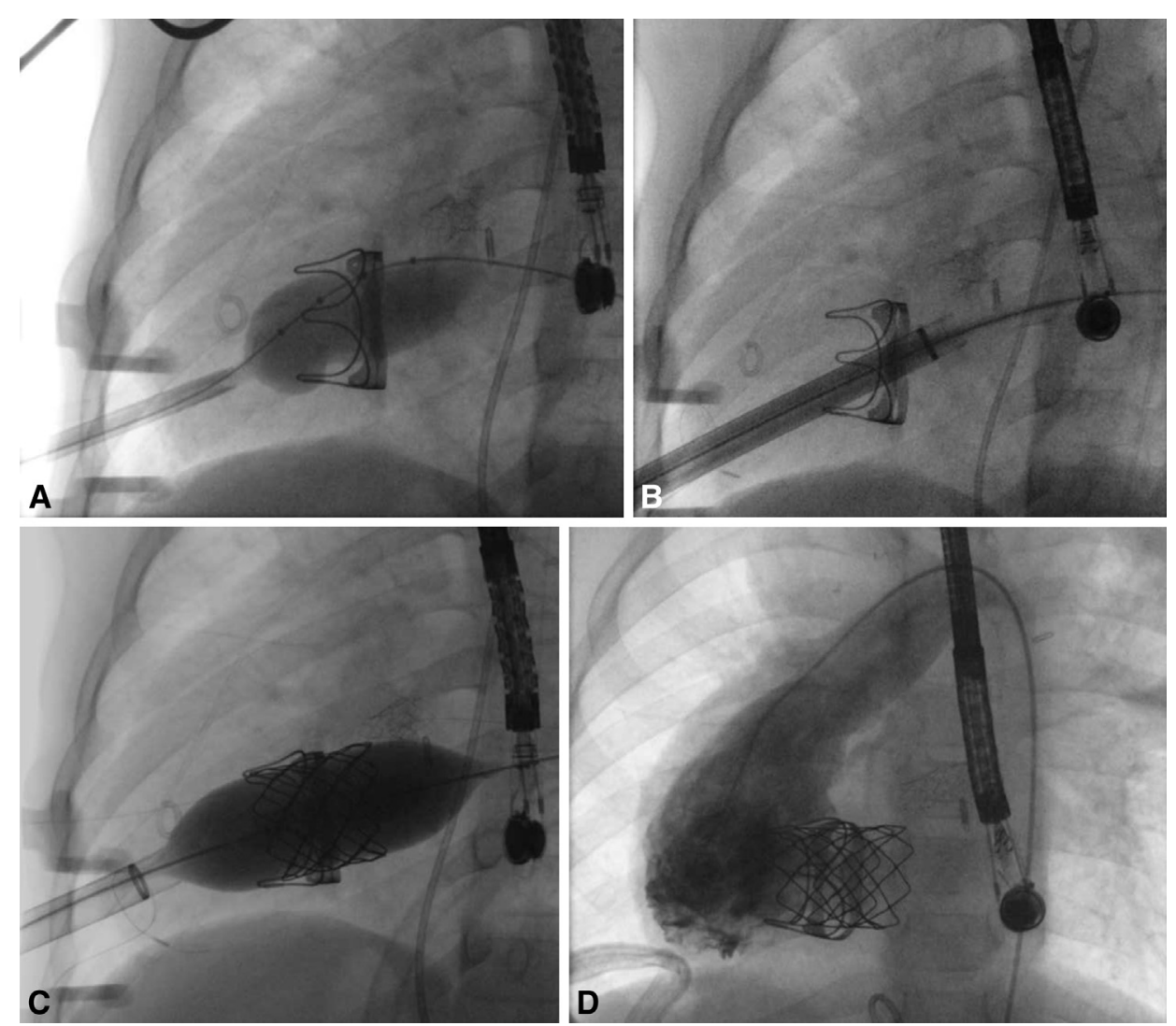

FIGURE 2. Transapical Melody valve-in-valve implantation in a mitral bioprosthesis. A, Balloon sizing. B, Positioning of a $21 \mathrm{~F}$ sheath over a guidewire through the bioprosthesis. C, Inflated valved stent within the bioprosthesis. D, Final ventriculography after successful implantation. 
course of plastic bronchitis or on the durability of the Melody valve in the mitral position.

\section{CONCLUSIONS}

Transapical implantation of a Melody valve in a mitral bioprosthesis is feasible even in a young child with a failing Fontan circulation; however, the patient had borderline intracardiac dimensions for this approach.

\section{References}

1. Gewillig M, Boshoff DE. Missing a sub-pulmonary ventricle: the Fontan circulation. In: Voelkel NF, Schranz D, eds. The right ventricle in health and disease. New York: Springer; 2015:135-57.
2. Ruel M, Chan V, Bédard P, Kulik A, Ressler L, Lam BK, et al. Very long-term survival implications of heart valve replacement with tissue versus mechanical prostheses in adults $<60$ years of age. Circulation. 2007;116(11 Suppl): I294-300.

3. Quinoñez LG, Breitbart R, Tworetsky W, Lock JE, Marshall AC, Emani SM Stented bovine jugular vein graft (Melody valve) for surgical mitral valve replacement in infants and children. J Thorac Cardiovasc Surg. 2014;148: 1443-9.

4. Cullen MW, Cabalka AK, Alli OO, Pislaru SV, Sorajja P, Nkomo VT, et al. Transvenous, antegrade Melody valve-in-valve implantation for bioprosthetic mitral and tricuspid valve dysfunction: a case series in children and adults. JACC Cardiovasc Interv. 2013;6:598-605.

5. Kliger C, Al-Badri A, Wilson S, Weiss D, Jelnin V, Kronzon I, et al. Successful first-in-man percutaneous transapical-transseptal Melody mitral valve-in-ring implantation after complicated closure of a para-annular ring leak. EuroIntervention. 2014;10:968-74.

\title{
EDITORIAL COMMENTARY
}

\section{The Robin Hood principle in the treatment of congenital heart disease: Taking technologic developments intended for adults and using it in kids}

\author{
Paul J. Chai, MD
}

See related article on pages e23-5.

In this issue of the Journal of Thoracic and Cardiovascular Surgery, Moysich and colleagues ${ }^{1}$ from Giessen, Germany, describe the successful transapical implantation of a Melody valve (Medtronic, Minneapolis, Minn) within a mitral bioprosthesis in a pediatric patient. This operation was performed in a 3-year-old child who previously had undergone a Fontan procedure and later a left atrioventricular valve replacement with a size 27 Medtronic Mosaic valve (Mosaic Tissue Valve; Medtronic). The Mosaic valve had severe regurgitation after 6 months, necessitating another valve replacement.

The successful use of the Melody valve in this manner to treat mitral valve disease is another example of how pediatric patients can benefit from technologic advances made in

\footnotetext{
From the Division of Cardiac, Thoracic, and Vascular Surgery, Department of Surgery, Columbia University Medical Center, New York, NY.

Disclosures: Author has nothing to disclose with regard to commercial support.

Received for publication May 20, 2015; accepted for publication May 20, 2015; available ahead of print June 12, 2015.

Address for reprints: Paul J. Chai, MD, New York-Presbyterian Morgan Stanley Children's Hospital (Central), 3959 Broadway, Room 275, New York, NY 10032

(E-mail: pjc2164@cumc.columbia.edu).

J Thorac Cardiovasc Surg 2015;150:e25-6

$0022-5223 / \$ 36.00$

Copyright (c) 2015 by The American Association for Thoracic Surgery

http://dx.doi.org/10.1016/j.jtcvs.2015.05.053
}

adult patients. Mitral valve disease in pediatric patients is a challenging problem, with few options available when mitral valve replacement is necessary. This has led some groups to explore new options for valve replacement therapy when needed. ${ }^{2}$

The use of adult transcatheter expandable valves is a promising option for mitral valve replacement in children.

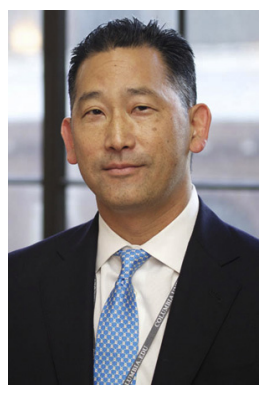
These valves can be implanted within a smaller annulus, do not require warfarin anticoagulation, and retain the ability to be expanded as the annulus of the child grows. Obviously, further study is necessary to evaluate long-term durability and complications; however, short-term to midterm results are promising.

This case report of the first successful "valve-in-valve" implantation of a Melody prosthesis in a pediatric patient with a Fontan circulation highlights the many options that may be available to pediatric patients in the future. Patients with Fontan circulations who have significant atrioventricular valve dysfunction can be difficult to treat, and the condition often leads to transplant unless the valve can be adequately repaired or replaced.

It is becoming increasingly beneficial to look to other areas in adult medicine for fresh solutions that could be applied in creative ways to patients with congenital heart 